Urban Design and Planning

Volume 166 Issue DP1

Integrating geographical information into urban safety research and planning

Ceccato
Proceedings of the Institution of Civil Engineers

Urban Design and Planning 166 February 2013 Issue DP1

Pages 15-23 http://dx.doi.org/10.1680/udap.11.00038

Paper 1100038

Received 16/09/2011_Accepted 11/04/2012

Keywords: information technology/safety \& hazards/town

and city planning

\title{
Integrating geographical information into urban safety research and planning
}

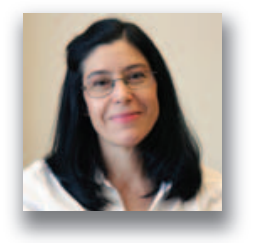

Vania Ceccato MSc, PhD

Docent, Associate Professor, School of Architecture and the Built Environment, Royal Institute of Technology, Stockholm, Sweden

The objective of this paper is to discuss the use of geographical information and spatial analytical methodologies in urban safety research and planning. Based on previous empirical examples, the paper investigates the advances and challenges of studying crime and perceived safety using geographical information and spatial analytical methodologies. Studies of crime and perceived fear at the micro-level in the urban landscape are also reviewed, followed by a discussion of ecological studies, which often search for associations between crime and socioeconomic characteristics of small areas. The use of geographical information and visualisation techniques has been incorporated into research and planning in public participation schemes and, more recently, into new methodologies aiming at predicting human movement patterns using real-time data. The paper reviews some of the current challenges for spatial urban safety research and concludes with prospects on the value of this form of analysis in the near future.

\section{Introduction}

Almost everything that happens, happens somewhere (Longley et al., 2005). Knowing where a phenomenon takes place can be critically important in understanding its nature and acting upon it. This is particularly important to those whose responsibility is to assess and/or ensure safety conditions in cities. The risk of being a victim of crime is not randomly distributed over space. Crimes tend to occur in particular geographical areas in a city; they may occur at certain hours of the day and even in association with specific demographic, land use, and socioeconomic aspects of the population (e.g. Ceccato, 2005, 2009; Eck and Weisburd, 1995; Haining, 2011). How individuals perceive risk and fear in outdoor city environments is also space dependent. Littered places, with clear signs of lack of social control, are often associated with high levels of fear (Wilson and Kelling, 1982). In this paper, it is argued that geographical information (GI), here defined as 'location and any other spatial related information', has been an important element in the discovery of these patterns of regularities of both crime and fear in city environments. Equally important has been the use of GI for planning purposes, particularly when the goal has been to target resources, more precisely, to tackle unsafe places and formulate preventive actions.

The use of GI in urban safety research is directly linked to the technological development of GI-based techniques both in academia and among planners and other professionals. The advent of computerised mapping systems as part of police command and control has led to the creation of software for visualising the growing amounts of geocoded crime data. In addition, geographical information systems (GIS) have made geographical analyses of crime data possible for a wide number of users, facilitating the integration of many types of data into a common spatial framework. The value of GIS becomes even greater when enhanced with spatial statistical techniques, qualitative information such as perceived safety, information from virtual environments and data from global positioning systems (GPS) and other tracking devices. The objective of this paper is to discuss the use and integration of GI (and spatial analytical tools) in urban safety research and planning. Focus is given to urban geographical spaces such as facades, streets, parks, districts and regions, excluding features of the domestic realm.

\section{The use of $\mathbf{G I}$ and spatial analytical methodologies in urban safety research}

Depending on the scale, GI can be represented by different features. A point can be a robbery on a street but it can also be a whole city in a region. Point data provide the exact location of individual measurement and are associated with a unique pair of co-ordinates. Lines can be rivers but also the intensity of fear in areas of a city perceived as risky. GI can also be continuous surfaces so data values are possible at each of an infinite number of locations. Polygons are popular in ecological analysis of crime and fear, often representing administrative units, such as districts or regions, for instance, county income. GI is often used to represent the 'real world' 
Urban Design and Planning

Volume 166 Issue DP1
Integrating geographical

information into urban safety

research and planning

Ceccato but may also be used to create virtual environments and scenarios in studies to train police officers and test people's reactions in different threat environments. GI data have also become tri-dimensional representations of reality, so points become spheres, polygons become cubic building structures and lines become rectangles that may be used to show links between gang members in a neighbourhood. As is shown in one example below, the multidimensionality of the GI can be linked to time but also to any attribute value, such as risk. The following sections discuss advances and challenges of integrating GI into urban safety research and planning guided by theories from criminology, architecture and planning.

\subsection{Streets and buildings: the micro-level of urban safety}

The role of city environments in crime causation has been the focus of theories since the 1960s. For instance, Jacobs (1961) coined the term eyes on street, stressing that the design of neighbourhoods has a role to play in defining opportunities for surveillance. According to Eck and Weisburd (1995), certain places might attract crime also because they draw people (some of whom are offenders) to the area, or because of how the place is managed, the desirability and accessibility of targets found at the site and the level of guardianship. These features are not static over time and space; they reflect people's routine activity (Cohen and Felson, 1979) over the city. An individual's activities and daily habits are rhythmic and consist of patterns. There is a greater risk of victimisation during periods when people are more often outside; in other words, different types of people, including both motivated offenders and potential victims, meeting in different places at different times. Yet crimes do not happen everywhere. One explanation for this is that 'potential criminals do not search through a whole city for targets; they look for targets within their more restricted awareness space' (Brantingham and Brantingham, 1984, p. 365). Coming from the same line of thought but directly focused on crime occurrence, Newman (1972) developed a theory based on the interaction between individuals and their environment, which he referred to as defensible space. Newman stated, for instance, that the type of building influences what occurs on the surrounding streets - that housing design can actually make individuals feel safe. A fundamental concept of this theory is that of natural surveillance: the 'capacity of physical design to provide surveillance opportunities for residents and their agents' (Newman, 1972, p. 78). Equally important were the ideas by Jeffery (1971) for the development of crime prevention through environmental design (CPTED), which is the approach to deterring criminal behaviour through environmental design.

There has been a recent debate between two schools of thought on how to design cities to minimise crime (Hillier and
Sahbaz, 2011). The 'new urbanist' position, as set out by Zelinka and Brennan (2001) in their book Safescape, is contrasted with the 'defensible space' position, originating in Oscar Newman's book Defensible Space (Newman, 1972). For instance, while private areas create defensible space and should be maximised according to defensible space theory, the new urbanists suggest exactly the opposite. The same applies to the role of mixed land uses. New urbanists defend mixed land use to maintain eyes on the streets, while their critics believe that mixed use reduces residential control and therefore increases crime. It is against this background that most research in this area has made use of GI in recent decades. One of the most prominent examples of the use of GI to assess safety in microenvironments is the work done by Bill Hillier, who is the pioneer of the methods for the analysis of spatial patterns known as 'space syntax'. This set of methods is based on a general theory of how people relate to space in built environments, including crime and safety research (see e.g. Hillier (2004)).

Different types of places increase or decrease crime in their immediate environment (for instance, a street corner) since they vary in type of facade, height and density of buildings, whether windows are facing the alleys, whether closed circuit television (CCTV) cameras and alarms are in place, and so on. Figure 1 shows a three-dimensional visualisation by Wolff and Asche (2009) that explores particular buildings of urban districts affected by a high number of robberies in their neighbourhood. For planning, this visualisation facilitates an intuitive communication of each building's distance from the closest crime scene and provides clues of how overall environments are influencing the types of social interaction in the area. For instance, the convergence of street corners seems to be particularly vulnerable to robbery.

\subsection{Neighbourhoods and regions: the ecology of crime and fear}

Why do certain neighbourhoods have more crime than others? This is the question that this branch of research tries to answer. In their seminal work on Chicago, Shaw and McKay (1942) argue that low economic status, ethnic heterogeneity and residential instability lead to community disorganisation, which results in a culture of violence and high rates of delinquency. According to Morenoff et al. (2001), the theory of social disorganisation was not operationalised until three decades later (Bursik, 1988; Kornhauser, 1978 ) as 'the inability of a community structure to realise the common values of its residents and maintain effective social controls.' Here the spatial analysis often aims at identifying associations between the social, economic, demographic and other characteristics of small areas and differences in crime rates and, in certain cases, collective efficacy (Sampson et al., 1997). Recent studies of this 


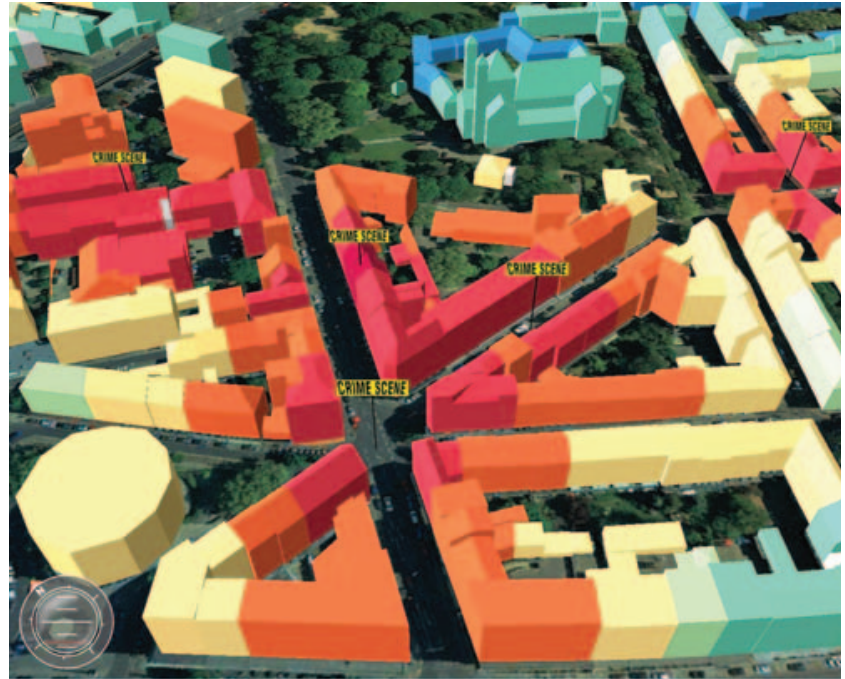

Minimum distance to closest crime site: $\mathrm{m}$

\begin{tabular}{|c|c|c|}
\hline Up to 5 & $\square$ Up to $86 \cdot 2$ (mean distance) & Up to 300 \\
\hline Up to 25 & $\square$ Up to 100 & Up to 400 \\
\hline Up to 50 & $\square$ Up to 150 & Up to 503 \\
\hline
\end{tabular}

Figure 1. Minimum distances of each building to the closest robbery crime scene (source: Wolff and Asche (2009), p. 154)

approach include GIS, area level data, spatial statistical techniques and modelling as common ingredients. Figure 2(a) illustrates an example of this approach by indicating the overlapping pattern of standardised assault rates by grid and main transportation lines in Tallin, Estonia.

In this example, crime data are attached to georeferenced areas or grids, which are often used to identify global (e.g. Moran's I) and local spatial clustering (e.g. Getis-Ord statistics), also known as hot spots of crime. These techniques utilise spatial autocorrelation, a fundamental property of spatial data whereby attribute values close together in geographical space tend to be more alike than attribute values that are further apart. Until recently, cluster techniques have been merely spatial, but now GI can be associated with time, using spacetime statistic and visualisation tools (e.g. Kulldorff, 1997; Nakaya and Yano, 2010) with the potential to predict crime events (Mohler et al., 2011). Spatial regression models (see Anselin, 1999) that take space arrangement of the data into account (e.g. using weight matrices to portray neighbourhood structure) are a common strategy when modelling the geography of crime and fear. Haining (2011) suggests that the analysis of area-referenced crime data has been made possible not only by statistical advances over the last few decades, but also by the availability of free software. Two recently edited handbooks by Fotheringham and Rogerson (2009) and Fischer and Getis (2010) provide an introduction to some of the theories and methods of exploratory and confirmatory spatial analysis. Haining also highlights the importance of free-of-charge packages: GeoDa is an easy-touse statistical package for modelling spatially referenced data with a continuously valued dependent variable; WinBUGS

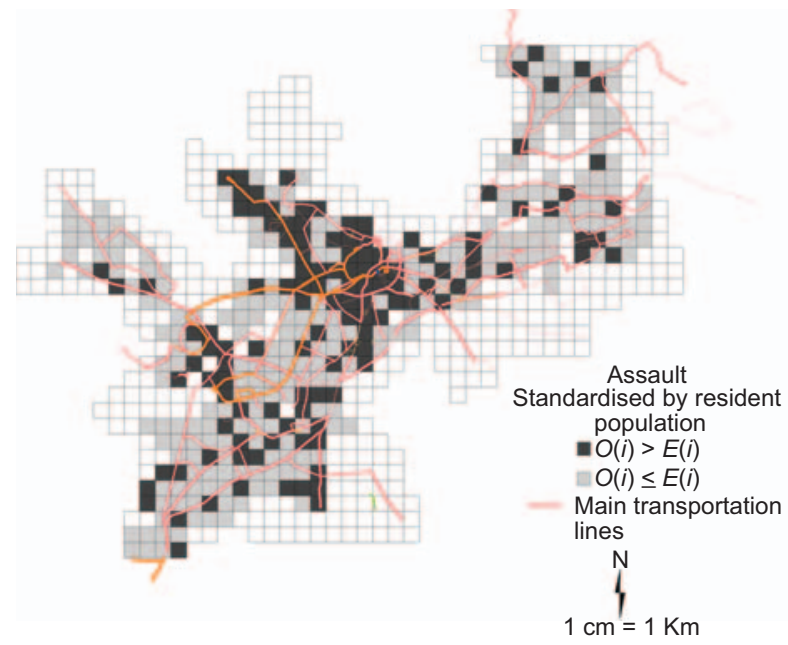

(a)

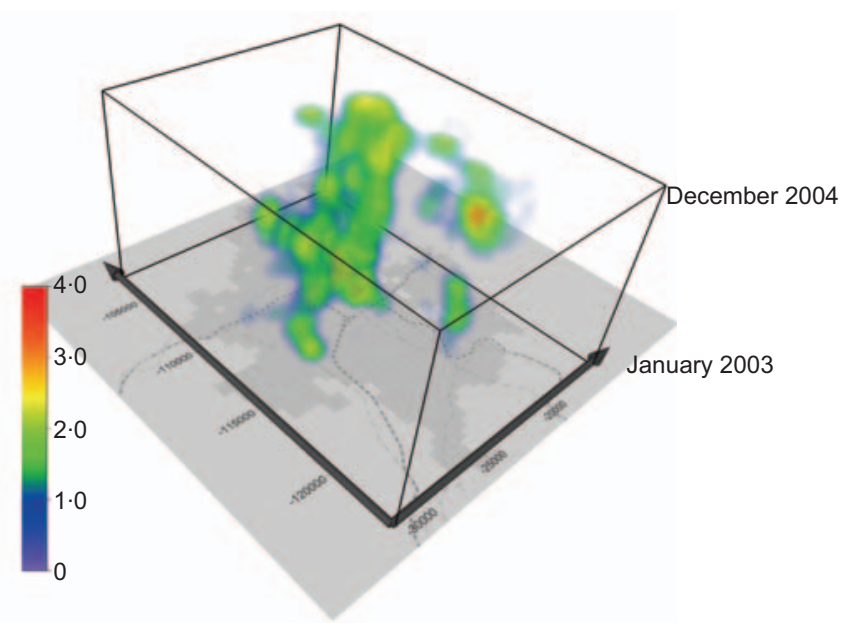

(b)

Figure 2. (a) Example of ecological research in urban criminology using grid data in Tallinn, Estonia (source: Ceccato (2009), p. 1621). (b) Alternating occurrence of crime clusters in a pair of cluster regions, Tokyo (source: Nakaya and Yano (2010), p. 236) 
Urban Design and Planning

Volume 166 Issue DP1
Integrating geographical

information into urban safety

research and planning

Ceccato enables modelling of spatially referenced count data. There is also an extensive spatial library of routines written in R.

Those studies that go beyond cluster detection are often able to indicate a number of statistically important ecological factors to explain the geography of crime or fear. However, there are a few criticisms against these studies. Studies based on ecological area data are often criticised for running the risk of ecological fallacy and suffer the consequences of the modifiable area unit problem (MAUP: for details, see Haining (2011)). So far, they have concentrated either on the neighbourhood conditions of crime location or on where offenders live, missing a great deal of information on people's whereabouts over time in the city. Another problem is that studies of this kind often rely on recorded police statistics, which have heterogeneous patterns of accuracy over space. Findings from these studies are too aggregated for the job of police officers working daily on the 'front line'. When perceived safety data are geocoded, extra attention must be paid to response rates by ecological area when used as model input. Although there is a need to make users (e.g. police officers, experts, planners) aware of what can (or cannot) be done using spatial statistics and GIS, there is no doubt that the combination of techniques and different data sources in GIS provides an approach for improving the knowledge base for strategic planning and long-term decision-making for ecological areas.

\subsection{Safety through the lens of those who experience the city}

In recent decades, GI and visualisation techniques have been integrated under the umbrella of public participation geographic information systems (PPGIS) and are increasingly powered by multimedia and internet tools. The formal definition of PPGIS remains nebulous (Tulloch, 2008) but it is often focussed on the integration of the rich knowledge base of communities, while minimising the structural knowledge distortion of traditional GIS applications and innovative techniques. Sketch maps from focus groups, including cognitive maps and products from multimedia, are an important source of insight into multiple realities and group interests. In urban safety research, the literature provides examples of how GI is captured either by using crime location or spatial representations of perceived safety thorough different degrees of participatory frameworks, stakeholders and users (Ceccato and Snickars, 2000; Matei et al., 2001). This development has imposed methodological, ethical and institutional challenges (for a review, see Sieber (2006) and Ramasubramanian (2008)). Furthermore, it would not be unfair to agree with $\mathrm{Yu}$ and $\mathrm{Yin}$ (2011, p. 213) who suggest that GIS still fall short in delivering online, distributed geographic information services and providing flexible, friendly GIS solutions for non-GIS trained users, which is of particular importance for urban safety and security studies. Overall, GI in PPGIS schemes has, according to Kwan (2002, p. 645), provided examples of 'the simultaneous empowering and marginalising effect of GIS in local politics, representations of multiple realities and local knowledge, and the scale-dependence of power-knowledge in GIS.' She also advocates a critical GIS perspective and more inclusive use of GI (e.g. working with gender and other social constructs such as ethnicity, class and place). For instance, she empirically explored this approach by using GIS for mapping women's life paths in space and time (Kwan, 2002), which was later followed by other GIS articles enriching feminist geographic research (e.g. Elwood, 2008)

A parallel development has been virtual environment (VE) simulation to assess individuals' perceptions of different safe/ unsafe scenarios. For instance, Park (2008) uses spatial data through a VE resembling a well-known, fear-generating urban area. Individuals were recruited to navigate the VE, making decisions at the decision points (Figure 3). Data describing individuals' choices, demographics and comments during postexperimental interviews form the basis for the study. Smith and Carter (2010) applied a similar methodology in a VE to test police and public awareness of public disorder events. Results suggest that VE can be used as a tool to provide a safe and controlled environment to assist police officer training as well as to gain insight into how the public experience public disorder problems.

\subsection{Individuals, interactions and flows: space-time dimensions of crime and fear}

For a crime to happen, a victim and an offender must be at exactly the same place at the same time. The intersection of these elements exemplifies how space as location plays a vital role in understanding crime and how crime occurs. This is the concept of space-and-time to which people are accustomed, in which space is the physical support of the way people live in time, as suggested by Stalder (2003, p. 3). With the current extensive use of telecommunications technology, a more appropriate concept of space has emerged - the space of flows (Castells, 1989, p. 146). This concept of space is based on human action and interaction occurring dynamically and at a distance - effected by way of telecommunications technology. This apparent space-less informational flow has an impact on crime geography and on our overall levels of anxiety.

First, crime becomes less dependent on space, and with that the fear of being a victim of crime may be fed by boundary-less 'glocal' forces. An individual living in Manhattan, New York may run the same risk of being victimised by computer fraud as someone living in the remote rural areas of Sweden or China. New types of computer-based communication may become facilitators for traditional crime as can be seen in the physical world (e.g. paedophiles looking for potential victims in youth 


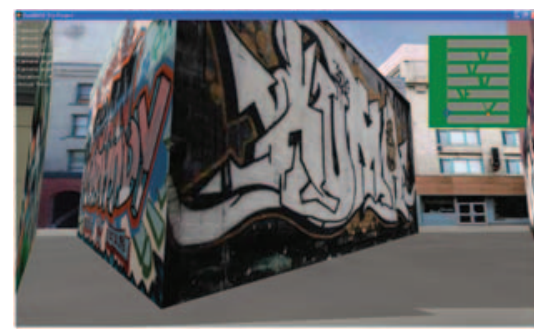

Decision point 1

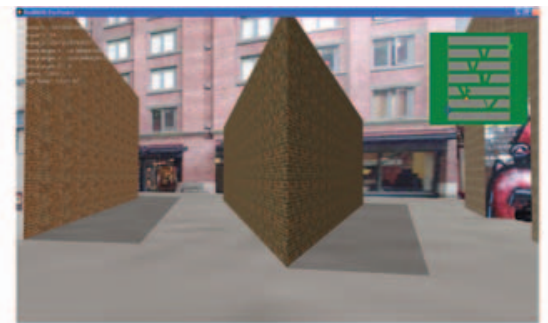

Decision point 2

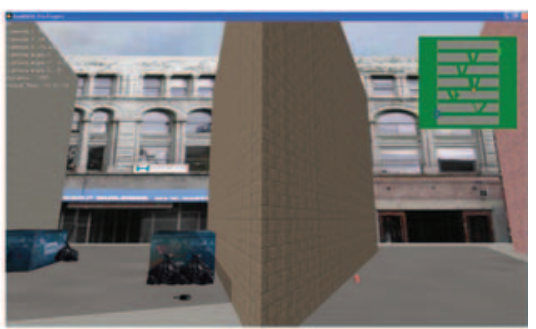

Decision point 3

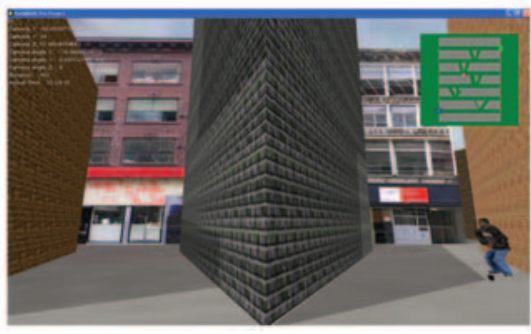

Decision point 4

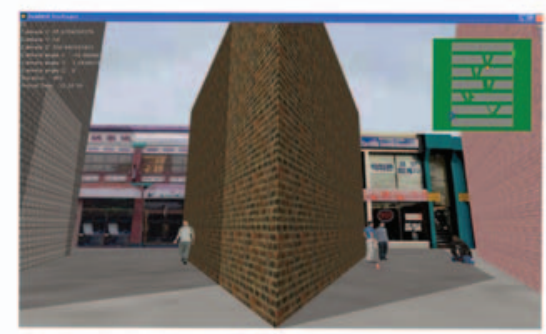

Decision point 5

Figure 3. Snapshots of each decision point in the VR environment

(source: Park (2008), p. 52)

chat forums). This imposes new challenges for crime prevention since law enforcement authorities have to find online criminals that may reside far from the police territorial jurisdiction. Second, information technology connects people without regard to their physical location but may leave tracks as soon as they move in space. The use of opportunistic sensors creates new means to track individual movement patterns by facilitating the continuous and relatively inexpensive collection of mobility data that can be used to develop continuous models of spatial interaction. Data of this kind can be useful for predicting realtime risk of a crime and for identifying groups of people and/or areas that may be perceived as unsafe during certain time windows, which is of importance in urban planning (Horner and O'Kelly, 2001). Methods to store and analyse these complex volumes of data are being developed. In their study using anonymised mobile phone users, Song et al. (2010) found a great predictability in user mobility regardless of the distance covered and across population groups. Other studies, based on the traditional space-time geography principles suggested by Hägerstrand 40 years ago, represent movement patterns as space-time prisms (Hägerstrand, 1970). However, this new set of data about people is not problem free (Giannotti and Pedreschi, 2008): privacy issues impose new ethical and institutional challenges for those who gather, share and analyse the data.

In practice, however, our understanding of the basic laws governing human movement remains limited for planning purposes owing to the lack of tools and appropriate methods to monitor and predict the time location of individuals. So far studies have been almost entirely data driven, often reflecting advances in computer engineering to map risk (Brunsdon et al., 2007), assessing general patterns of spatial behaviour (Gonzalez et al., 2008; Song et al., 2010) and in some cases testing whether regional boundaries defined by governments respect the more natural ways that people interact across space (Ratti et al., 2010). The possibility of using real-time location data has, for instance, opened up a number of new research questions and perhaps, answers to old ones. Examples include work by the Massachusetts Institute of Technology's (MIT's) Senseable City Lab, UrbanSense at University of California, Los Angeles (UCLA), Spatial Information design lab at Columbia University and the $i$-Mobility lab at Kungliga Tekniska högskolan (KTH, Royal Institute of Technology), Sweden. At the present time, the $i$-Mobility lab receives realtime data streams from hundreds of automated vehicle identification cameras in Stockholm and GPS receivers located in more than 1500 taxis operating in the Stockholm region. These projects serve as examples to illustrate the unlimited opportunities mobile communications offer today to understand urban activities and monitor them over time, explore human interaction with the local environment to improve health or safety, or analyse the use of space. In theory, more individuals being tracked over time and space means that more people would feel safer; given that individuals can more easily alert friends or police to any danger they may encounter. 
Urban Design and Planning

Volume 166 Issue DP1
Integrating geographical

information into urban safety

research and planning

Ceccato
However, in the case of mobile phones, Nasar et al. (2007, p. 863) found that although using a mobile phone to call for help has value, 'the increased perceived safety associated with it may lead individuals to engage in risky behaviour that could increase their chances of becoming a victim.'

Geographical information has also been used in longitudinal studies in urban criminology. Wikström et al. (2010) incorporate information on individuals' exposure to urban environments to predict offending. Although spatial data were collected using traditional frameworks (computer-based survey), GIS was used to visualise the individual activity fields of 700 children (Figure 4). For the police investigation work, GI has proven to be useful in finding criminals. By identifying the offenders' modus operandi, place of residence and offence location, police forces can narrow down a number of suspects a process called geographic profiling. The technique assesses the behavioural, social and psychological aspects of the offender, considering that certain personality types exhibit similar behavioural patterns, and the knowledge of these patterns can assist in the investigation of the crime and of potential suspects (Rossmo, 2000). The use of GI is also an essential part of the analysis of the victims of outdoor rape. In an ongoing study using GIS and spatial analysis, Ceccato (2011) analyses the nature of places where two-thirds of rapes occur in the Swedish capital, Stockholm. Patterns of spatial regularities of rape locations and victims' mobility are geographically compared with places in the urban landscape that women commonly fear. The study also brings to light the victim's perspective (so far missing in the geographical literature) of the crime's location in relation to the overall urban

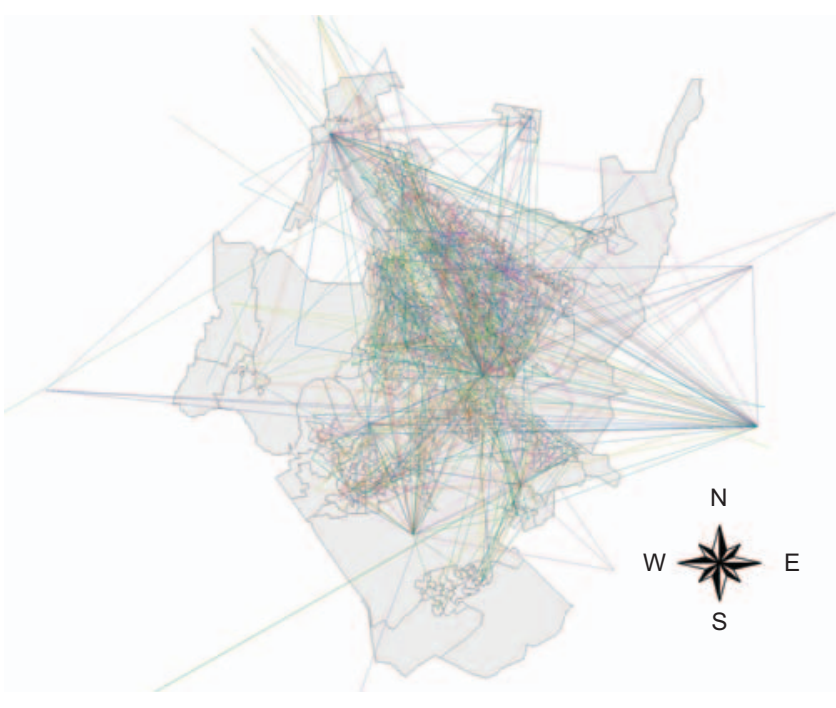

Figure 4. Activity fields of young people, Peterborough, UK (source: based on Wikström et al. (2010)) environment. Doing this provides support for interventions that may prevent outdoor rapes from happening and therefore contributes to urban safety, one of many dimensions of urban sustainability.

\section{Drawing conclusions and looking ahead}

In this paper urban safety research using GI and related technologies has been reviewed. These studies show examples of the best evidence of the tools and data available today and to what extent they can be used to provide information about patterns of crime and fear in urban environments.

Before discussing future research and the complexities awaiting researchers, there are still two urgent issues to be aware of when working with GI and urban safety. The first relates to data availability and the quality of official crime statistics. Although GIS has made geographical analyses of georeferenced data possible for a wide number of users, crime data still show quality concerns. Under-reporting is a known cause of lack of reliability in databases of offences, which vary by crime type and over space. Other possible sources of inaccuracy include lack of information about the event from the victim or because the police officer fails to record the event properly. Data quality may also be affected by handling procedures, such as poor geocoding. Missing data can be remedied by exploring some of the properties of spatial data, such as spatial autocorrelation, but it is important to be aware that data quality is still an important barrier to both research and planning.

The second issue concerns the selection of the appropriate technique in relation to the application's goals, which has, of course, to do with the choice of theoretical framework guiding the analysis. Although urban safety research constitutes a united multidisciplinary research field, in practice it is developed by distinct types of professionals who do not always follow the same theoretical principles. For instance, while the analysis of micro-spaces and crime has mostly been the interest of architects, geographers and criminologists have extensively explored ecological research. Also, urban planners have often emphasised PPGIS, while computer scientists have focused on recent developments in the use of individual movement data. This seems to be a natural development, as some problems better fit certain types of professionals, but this also imposes a price in terms of advancement in research and policy actions. Reality demands more integrated, holistic and cross-disciplinary theories and methods that are capable of guiding (and dealing with) an ever-increasing volume of space and time data; this constitutes the new frontier of spatial research in urban safety and planning practices.

Overall, the challenges in using GI and GI-related techniques as support for research and planning are not merely linked to 
the data, theory or tools themselves, but to the way in which they are utilised. For instance, in ecological analysis there is a constant risk of so-called ecological fallacy, which occurs when correlated, aggregated values over a specific geographical area are related to the individual level. There is also the risk that maps may be used to create images that cannot be generalised for the whole group, and a distorted map may turn out to be a tool for exclusionary planning practices instead of providing a basis for more just actions. An innovative way to avoid place or group stigmatisation is the use of virtual environments. Future research should devote time to the critical assessment of the role of GIS and related tools to fit the demands of evidence-based planning and whether and how these tools are making a difference in policy action.

For the first time it is possible to capture snapshots of movement in tiny slices of time of a pulsing city. For planning safety, this development potentially impacts on how safety services are guided by the level of detailed data on individuals in time and space and the level of interactivity they may share with agencies and data holders. Better grounds to assess the risk of crime can help individuals to make dynamic decisions as they move, as well as support police enforcement to be in the right place at the right time. Although our daily mobility seems to be characterised by a deep-rooted regularity (Song et al., 2010), explicit predictions on user whereabouts can be explored in future research by using data-mining algorithms (e.g. Eagle and Pentland, 2006), turning the patterns of regularities into actual mobility predictions. For urban safety research, this means that measurements through opportunistic sensors can be used to gather data on individuals' behaviour, their risks and safety perceptions in real time across city environments. One application of these new information sources could be to alter people's perceptions of crime incidence and moderate their safety fears. In the wrong hands, perpetrators could perhaps use this information to identify the best places to commit crimes, especially if the information includes rates of detection and successful prosecution by police districts, and so on. Although mobility data represent a very useful source of information, the sharing of user locations and movements raises privacy concerns as well. Future research must also focus on development of sophisticated privacy-enhancing solutions to protect the location and mobility information of the individuals from potential privacy attacks, and more importantly, to understand how these concerns affect the future adoption of related technology. A discussion of ethical issues of data ownership and sharing, and the respective role of public and private institutions upon this development, is crucial. In this context it is essential to be able to review the experiences from using GI in urban safety research, as has been done in this paper. Although barriers of different types are unlikely to be resolved in the short term, the forecast is that a rapid development will occur in this field of research. It is up to us to catch up with it!

\section{Acknowledgements}

The author would like to thank Tigran Haas and the anonymous reviewers for their helpful thoughts, comments and suggestions. The support of Formas (grant reference 2502009-479) is gratefully acknowledged by the author.

\section{REFERENCES}

Anselin L (1999) The future of spatial analysis in the social sciences. Geographic Information Sciences 5(2): 67-76.

Brantingham P and Brantingham P (1984) Patterns in Crime. Macmillan, New York, USA.

Brunsdon C, Corcoran J and Higgs G (2007) Visualising space and time in crime patterns: a comparison of methods. Computers, Environment and Urban Systems 31(1): 52 75.

Bursik RJ (1988) Social disorganisation and theories of crime delinquency: problems and prospects. Criminology 26(4): $519-551$

Castells M (1989) The Informational City: Information Technology, Economic Restructuring, and the UrbanRegional Process. Basil Blackwell, Oxford, UK.

Ceccato V (2005) Tools in the spatial analysis of offences: evidence from Scandinavian cities. In GIS for Sustainable Development (Campagna M (ed.)). Taylor and Francis, Boca Raton, USA, pp. 267-287.

Ceccato V (2009) Crime in a city in transition: the case of Tallinn, Estonia. Urban Studies 46(8): 1593-1610.

Ceccato V (2011) Plats som motverkar våld (places that prevent violence). Miljöforskning 4. See http://miljoforskning. formas.se/sv/Nummer/Oktober-2011/Innehall/ Temaartiklar/Plats-som-motverkar-vald/ (accessed 06/12/ 2012).

Ceccato V and Snickars F (2000) Adapting GIS technology to the needs of local planning. Environment and Planning B 27(6): 923-938.

Cohen LE and Felson M (1979) Social change and crime rate trends: A routine activity approach. American Sociological Review 44(4): 588-608.

Eagle N and Pentland A (2006) Reality mining: sensing complex social systems. Journal Personal and Ubiquitous Computing 10(4): 255-268.

Eck JE and Weisburd D (1995) Crime places in crime theory. In Crime and Place, Crime Prevention Studies (Clarke RV (ed.)). Willow Tree Press, Monsey, New York, USA, vol. 4.

Elwood S (2008) Volunteered geographic information: future research directions motivated by critical, participatory, and feminist GIS. GeoJournal 72(3-4): 173-183.

Fischer M and Getis A (2010) Handbook of Applied Spatial Analysis. Springer, Heidelberg, Germany. 
Fotheringham AS and Rogerson PA (2009) The SAGE Handbook of Spatial Analysis. Sage, London, UK.

Giannotti F and Pedreschi D (eds) (2008) Mobility, Data Mining and Privacy - Geographic Knowledge Discovery. Springer, Berlin, Germany.

Gonzalez MC, Hidalgo CA and Barabasi AL (2008) Understanding individual human mobility patterns. Nature 453: 779-782.

Hägerstrand T (1970) What about people in regional science? Papers in Regional Science Association 24: 7-21.

Haining R (2011) Ecological analysis of urban offence and offender data. In The Urban Fabric of Crime and Fear (Ceccato V (ed.)). Springer, Dordrecht, the Netherlands, pp. 141-163.

Hillier B (2004) Can streets be made safe? Urban Design International 9: 31-45.

Hillier B and Sahbaz O (2011) Safety in numbers: high resolution analysis of crime in street networks. In The Urban Fabric of Crime and Fear (Ceccato V (ed.)). Springer, Dordrecht, the Netherlands, pp. 111-137.

Horner MW and O'Kelly MES (2001) Embedding economies of scale concepts for hub networks design. Journal of Transport Geography 9(4): 255-265.

Jacobs J (1961) The Death and Life of Great American Cities. Vintage Books, New York, USA.

Jeffery CR (1971) Crime Prevention Through Environmental Design. Sage Publications, Beverly Hills, CA, USA.

Kornhauser R (1978) Social Sources of Delinquency. University of Chicago Press, Chicago, IL, USA.

Kulldorff M (1997) A spatial scan statistic. Communications in Statistics: Theory and Methods 26(6): 1481-1496.

Kwan MP (2002) Feminist visualization: re-envisioning GIS as a method in feminist geographic research. Annals of the Association of American Geographers 92(4): 645-661.

Longley PA, Goodchild MF, Maguire DJ and Rhind DW (2005) Geographic Information Systems and Science. John Wiley, Chichester, UK.

Matei S, Ball-Rokeach SJ and Qiu JL (2001) Fear and misperception of Los Angeles urban space: a spatialstatistical study of communication-shaped mental maps. Communication Research 28(4): 429-463.

Mohler G, Short MB, Brantingham PJ and Tita G (2011) Selfexciting point process modeling of crime. Journal of the American Statistical Association 106(493): 100-108.

Morenoff J, Sampson RJ and Raundenbush S (2001) Neighbourhood inequality, collective efficacy, and the spatial dynamics of homicide. Criminology 39(3): $517-560$.

Nakaya T and Yano K (2010) Visualising crime clusters in a space-time cube: an exploratory data-analysis approach using space-time kernel density estimation and scan statistics. Transactions in GIS 14(3): 223-239.

Nasar J, Hecht P and Wener R (2007) 'Call if you have trouble' mobile phones and safety among college students. International Journal of Urban and Regional Research 31(4): 863-873.

Newman $O$ (1972) Defensible Space: Crime Prevention through Urban Design. Macmillan, New York, USA.

Park AJ (2008) Modeling the Role of Fear of Crime in Pedestrian Navigation. PhD thesis, Simon Fraser University, BC, Canada.

Ramasubramanian L (2008) PPGIS: state of the practice. In Geographic Information Science and Public Participation, Advances in Geographic Information Science (Balram S and Dragicevic S (eds)). Springer-Verlag, Berlin, Germany, pp. 49-74.

Ratti C, Sobolevsky S, Calabrese F et al. (2010) Redrawing the map of Great Britain from a network of human interactions. PLoS ONE 5(12): e1424, 12.

Rossmo DK (2000) Geographic Profiling. CRC Press, Boca Raton, FL, USA.

Sampson RJ, Raundenbush SW and Earls F (1997) Neighborhoods and violent crime: A multilevel study of collective efficacy. Science 277(5328): 918-924.

Shaw CR and McKay HD (1942) Juvenile Delinquency and Urban Areas. University of Chicago Press, Chicago, IL, USA.

Sieber R (2006) Public participation geographic information systems: a literature review and framework. Annals of the Association of American Geographers 96(3): 491507.

Smith SP and Carter T (2010) A virtual environment to test police and public awareness of anti-social behaviour indicators. International Journal of Police Science and Management 12(4): 548-566.

Song C, Qu Z, Blumm N and Barabasi AL (2010) Limits of predictability in human mobility. Science 327(5968): 1018 1021.

Stalder F (2003) The Status of Objects in the Space of Flows. $\mathrm{PhD}$ thesis, University of Toronto, Canada.

Tulloch D (2008) Public participation GIS (PPGIS). In Encyclopedia of Geographic Information Science (Kemp K (ed.)). Sage, London, UK, pp. 351-353.

Wikström PO, Ceccato V, Hardie B and Treiber K (2010) Activity fields and the dynamics of crime: advancing knowledge about the role of the environment in crime causation. Journal of Quantitative Criminology 26(1): 5587.

Wilson JQ and Kelling GL (1982) The police and neighborhood safety: Broken windows. Atlantic Monthly 249: 29-38.

Wolff $\mathrm{M}$ and Asche H (2009) Exploring crime hotspots: geospatial analysis and 3D Mapping. Proceedings of REAL CORP 2009, Tagungsband, 22-25 April 2009, pp. 147-156, see http://www.corp.at.

Yu D and Yin J (2011) Internet GIS and system dynamic modeling in urban public safety and security studies: a conceptual framework. In New Horizons in Web-Based 
Learning - ICWL 2010 Workshops. Springer, Heidelberg, Germany, pp. 207-216.

Zelinka A and Brennan D (2001) Safescape: Creating Safer,
More Liveable Communities through Planning and Design. Planner Press, American Planning Association (APA), Chicago, IL, USA

\section{WHAT DO YOU THINK?}

To discuss this paper, please email up to 500 words to the editor at journals@ice.org.uk. Your contribution will be forwarded to the author(s) for a reply and, if considered appropriate by the editorial panel, will be published as discussion in a future issue of the journal.

Proceedings journals rely entirely on contributions sent in by civil engineering professionals, academics and students. Papers should be 2000-5000 words long (briefing papers should be 1000-2000 words long), with adequate illustrations and references. You can submit your paper online via www.icevirtuallibrary.com/content/journals where you will also find detailed author guidelines. 